\title{
Cardiac hypertrophy with preserved contractile function after selective deletion of GLUT4 from the heart
}

\author{
E. Dale Abel, ${ }^{1}$ Helen C. Kaulbach, ${ }^{1}$ Rong Tian, ${ }^{2}$ James C.A. Hopkins, ${ }^{2}$ John Duffy, ${ }^{3}$ \\ Thomas Doetschman, ${ }^{3}$ Timo Minnemann, ${ }^{1}$ Mary-Ellen Boers, ${ }^{1}$ Ed Hadro, ${ }^{1}$ \\ Corinna Oberste-Berghaus, ${ }^{1}$ William Quist, ${ }^{4}$ Bradford B. Lowell, ${ }^{1}$ Joanne S. Ingwall, ${ }^{2}$ \\ and Barbara B. Kahn ${ }^{1}$
${ }^{1}$ Division of Endocrinology and Metabolism, Beth Israel Deaconess Medical Center and Harvard Medical School, Boston, Massachusetts 02215, USA
${ }^{2}$ Nuclear Magnetic Resonance Laboratory for Physiological Chemistry, Cardiovascular Division, Department of Medicine, Brigham and Women's Hospital, Boston, Massachusetts 02115, USA
${ }^{3}$ Department of Molecular Genetics, University of Cincinnati, Cincinnati, Ohio 45267, USA
${ }^{4}$ Department of Pathology, Beth Israel Deaconess Medical Center and Department of Cardiac Surgery, Children's Hospital, Boston, Massachusetts 02115, USA

Address correspondence to: E. Dale Abel, Division of Endocrinology and Metabolism, Beth Israel Deaconess Medical Center, Research North/BIDMC, PO Box 15707, Boston, Massachusetts 02215, USA. Phone: (617) 667-2151; Fax: (617) 667-2927; E-mail: dabel@caregroup.harvard.edu.

Helen C. Kaulbach and Rong Tian contributed equally to this work.

Received for publication June 15, 1999, and accepted in revised form October 26, 1999.

Glucose enters the heart via GLUT1 and GLUT4 glucose transporters. GLUT4-deficient mice develop striking cardiac hypertrophy and die prematurely. Whether their cardiac changes are caused primarily by GLUT4 deficiency in cardiomyocytes or by metabolic changes resulting from the absence of GLUT4 in skeletal muscle and adipose tissue is unclear. To determine the role of GLUT4 in the heart we used cre-loxP recombination to generate $\mathrm{G} \mathrm{H}^{-/-}$mice in which GLUT4 expression is abolished in the heart but is present in skeletal muscle and adipose tissue. Life span and serum concentrations of insulin, glucose, FFAs, lactate, and $\beta$-hydroxybutyrate were normal. Basal cardiac glucose transport and GLUT1 expression were both increased approximately 3-fold in $\mathrm{G}^{2} \mathrm{H}^{-/-}$mice, but insulin-stimulated glucose uptake was abolished. $\mathrm{G} 4 \mathrm{H}^{-/-}$mice develop modest cardiac hypertrophy associated with increased myocyte size and induction of atrial natriuretic and brain natriuretic peptide gene expression in the ventricles. Myocardial fibrosis did not occur. Basal and isoproterenolstimulated isovolumic contractile performance was preserved. Thus, selective ablation of GLUT4 in the heart initiates a series of events that results in compensated cardiac hypertrophy.

J. Clin. Invest. 104:1703-1714 (1999).

\section{Introduction}

To meet its substantial energy requirements, the heart is capable of metabolizing a variety of substrates. Cardiac function is therefore very tightly linked to substrate uptake and utilization. Under resting conditions, the heart derives about $70 \%$ of its energy from the oxidation of lipids, and the remainder primarily from glycolysis and glucose oxidation (1). Under some physiological conditions such as exercise (2), and in certain pathologic states such as hyperthyroidism (3), ischemia $(4,5)$, hypertrophy, and congestive heart failure $(6,7)$, the heart becomes increasingly dependent upon glucose to meet its metabolic demands. Glucose transport is rate limiting for glucose metabolism (8). Glucose enters the heart via the facilitative glucose transporters GLUT1 and GLUT4 (9). The GLUT1 transporter is widely expressed, and is the major mediator of glucose uptake in tissues such as the brain, the blood-brain barrier, erythrocytes, and endothelial cells $(9,10)$. In contrast, expression of the GLUT4 transporter is limited primarily to muscle (skeletal and cardiac) and adipose tissue, and is the most abundant isoform in these tissues, which also express GLUT1 $(9,10)$. In the heart, GLUT4 translocates to the plasma membrane in response to insulin (11-13), ischemia (12-14), hypoxia (15), and high-frequency contraction (16). Although these stimuli also result in the translocation of GLUT1, it is likely that GLUT4-mediated uptake represents the major mechanism by which the heart increases glucose uptake under these circumstances (17). In contrast to its role in adipose tissue and skeletal muscle (17-19), GLUT1 is a major mediator of basal cardiac glucose uptake $(20,21)$.

Glucose transporter expression in the heart is altered in various pathologic states. In untreated diabetes, there is profound downregulation of GLUT4 $(22,23)$. GLUT1 expression is also downregulated, but the changes are less marked than those described for GLUT4 $(24,25)$. It has been proposed that these changes in glucose transporter expression contribute to myocardial dysfunction in diabetics (25). The increased myocardial glucose uptake observed in various models of cardiac hypertrophy $(6,7,26)$ is uni- 
formly associated with increased expression of GLUT1, with no increase (7), or even a decrease, in GLUT4 expression (26). Agents that induce cardiac myocyte hypertrophy have recently been shown to induce GLUT1 expression at the level of transcription (27). The mechanisms governing the differential regulation of GLUT4 and GLUT1 in this and other pathophysiological states $(20,21,28)$, and the relationship between altered glucose transporter expression and cardiac function, are incompletely understood. One approach to address these issues is to alter cardiac glucose transporter expression in transgenic mice.

The phenotype of GLUT4-null mice, in which GLUT4 expression was ablated in all tissues in which it is normally expressed (heart, skeletal muscle, and adipose tissue), provided additional evidence that changes in the cardiac expression of glucose transporters can have profound effects on cardiac structure and function (29). These GLUT4-null mice exhibit significant growth retardation and die prematurely. A striking aspect of this phenotype is the development of marked cardiac hypertrophy (a greater than 2-fold increase in heart weight to body weight ratio), upregulation of cardiac GLUT1 expression, and heart failure. These mice are hyperinsulinemic and have reduced concentrations of cardiac fuels such as $\beta$-hydroxybutyrate, FFAs, and lactate, probably because of GLUT4 deficiency in adipose tissue and skeletal muscle. Mice that are heterozygous for the GLUT4null allele also develop cardiac hypertrophy and histological changes consistent with diabetic cardiomyopathy (30). These mice are hyperinsulinemic, and the majority of these animals develop hypertension and diabetes. Furthermore, normalization of glucose homeostasis by transgenic re-expression of GLUT4 in the skeletal muscle of these mice results in a reversal of the cardiac pathology (31). Thus it is not clear whether all of the cardiac changes are due to the absence of or reduction in GLUT4 expression, or whether the development of cardiac hypertrophy in this interesting model is at least partially due to an altered metabolic milieu that may have independent effects on cardiac structure and function.

Therefore, the aim of this study was to determine the effect of altered cardiac glucose transporter expression in vivo on cardiac contractile performance and the development of cardiac hypertrophy. To achieve this, we used Cre-loxP-mediated gene recombination to generate mice with cardiac-specific inactivation of the GLUT4 gene. With this approach we could study the role of the transporter in the heart in the absence of compensatory metabolic changes that may occur when the gene is also inactivated in skeletal muscle, adipose tissue, or both. Herein we report that mice with cardiacselective deletion of GLUT4 develop modest cardiac hypertrophy with preserved contractile function.

\section{Methods}

GLUT4 loxP mice. The GLUT4 gene was cloned from a mouse $129 \lambda$ bacteriophage library. An 18-kb fragment containing the coding region, $4 \mathrm{~kb}$ of $5^{\prime}$ flanking sequence, and $8 \mathrm{~kb}$ of $3^{\prime}$ flanking sequence was used to construct the targeting vector whose $5^{\prime}$ boundary was a HindIII site 700 bp upstream of exon 1 . The introns that flank exon 10 (which encodes the external and internal glucose binding sites) were modified by introduction of loxP sites (32). The $5^{\prime}$ intron was isolated by subcloning a fragment of the GLUT4 gene from the SacII site that is proximal to exon 5 to a unique SacI site in exon 10. The proximal $\operatorname{lox} P$ site was then blunt-end ligated into a unique $A c c$ I site in the $5^{\prime}$ intron (Figure 1a). The $3^{\prime}$ intron was isolated by subcloning a fragment of the GLUT4 gene from the SacI site in exon 10 to an EcoRI site in exon 11. The distal loxP site was then blunt-end ligated into a unique HindIII site in the $3^{\prime}$ intron (Figure 1a). The orientations of the loxP sequences were verified by sequencing, and the vector was reconstituted with 2 clones containing the loxP sites in the same orientation. The gene for neomycin resistance under the control of the phosphoglycerate kinase promoter was cloned into a BamHI site $1.5 \mathrm{~kb}$ downstream of the final coding exon, with an additional $4 \mathrm{~kb}$ of homologous DNA downstream of the neomycin gene (Figure 1a). The vector was cloned into the plasmid Bluescript (Stratagene, La Jolla, California), linearized with NotI, and electroporated into J1 ES cells as described previously $(33,34)$. G418-resistant colonies were expanded and genotyped by Southern blotting after digestion with Bam HI, probing with a 2-kb BamHIHindIII fragment immediately upstream of the beginning of the targeting vector. Targeted clones were identified by the presence of a BamHI site in the loxP insert that resulted in a $7-\mathrm{kb}$ band, rather than the $10-\mathrm{kb}$ endogenous allele (Figure 1b). Additional confirmation of the integrity of the targeted allele was performed by probing the BamHI-digested DNA with exon 10, which revealed the expected $1.1-\mathrm{kb}$ modified sequence, and with the neomycin-resistance gene sequence, which produced the predicted $2.5-\mathrm{kb}$ band (data not shown). Three clones with homologous integration of the GLUT4 loxP gene were identified out of 120 clones screened; these were injected into the blastocysts of C57BL6 mice. Chimeric mice were obtained and germline transmission was confirmed by Southern blotting.

Cardiac cre transgenic mice. Mice with cardiac-specific expression of cre recombinase (32) were generated by injection into mouse zygotes of the FVB strain, a transgene in which the expression of the cDNA of cre recombinase and the $3^{\prime}$ untranslated region (UTR) of the buman $\beta$-actin gene was directed by the murine $\alpha$-myosin heavy-chain promoter (Figure 1c) (35). A 6-kb BamHISall fragment of the $\alpha-M H C$ gene that contains the promoter and the first 2 noncoding exons was cloned into Bluescript (Stratagene). A cDNA containing cre recombinase (a kind gift of the Department of Anatomy, University of California-San Francisco, San Francisco, California, USA), with a nuclear localization sequence cloned upstream of the buman $\beta$-actin UTR, was then cloned as a SalI-KpnI fragment downstream of the $\alpha$ $\mathrm{MHC}$ promoter. The transgene was released by a KpnINotI digest before injection. The presence of the cre 
transgene was confirmed by Southern blotting of tailderived genomic DNA, which was digested with Bam HI and probed with a cDNA fragment containing the first $400 \mathrm{bp}$ of the cre recombinase gene. Cre transgenic mice were identified by the presence of a specific 6-kb band.

Cardiac-selective GLUT4-ablated mice. The generation of mice with cardiac-specific GLUT4 ablation designated $\mathrm{G}_{4} \mathrm{H}^{-/-}$(GLUT4 heart-null) was achieved by crossing mice bearing the modified GLUT4 gene containing loxP sites with transgenic mice with cardiac-specific expression of the enzyme cre recombinase. Crossing of cre transgenic mice with GLUT4 loxP heterozygotes (+/lox) resulted in the generation of mice that harbored the cre transgene and that were heterozygous for the GLUT4 loxP allele $\left(\mathrm{cre}^{+} /\right.$lox $)$. Cardiac-specific knockouts were then generated by crossing these cre $+/$ lox transgenic mice with GLUT4 loxP heterozygotic mice. The presence of the cre transgene and the modified loxP alleles were verified by PCR in addition to Southern blotting as described above. For the Cre transgene the following primers were used: 5'-ATG TCC AAT TTA CTG ACC G -3' and 5'-CGC CGC ATA ACC AGT GAA AC-3'. PCR conditions were as follows: 1 cycle at $94^{\circ} \mathrm{C}$ for 2 minutes, then 35 cycles each at $93^{\circ} \mathrm{C}$ for 40 seconds, $63^{\circ} \mathrm{C}$ for 30 seconds, and $72^{\circ} \mathrm{C}$ for 45 seconds, and finally 1 cycle at $72^{\circ} \mathrm{C}$ for 10 minutes. Primers for insulin receptor substrate 1 (5'-GTC TTG CTC AGC CTC GCT AT-3' and 5'-ACA GCG TGA ATT TTG GAG TCA GAA - $3^{\prime}$ ) were used as internal controls. The primers used for identifying the presence of the loxP allele (5'-ACC CAT GCC GAC AAT GAA GTT AC- $3^{\prime}$ and $5^{\prime}$ GGC TGT GCC ATC TTG ATG ACC- $3^{\prime}$ ) were designed to amplify the intron between exon 9 and exon 10. The presence of the loxP allele would give a band that was $126 \mathrm{bp}$ longer than the wild-type intron. PCR conditions were 1 cycle at $94^{\circ} \mathrm{C}$ for 2 minutes and 35 cycles each at $93^{\circ} \mathrm{C}$ for 30 seconds, $63^{\circ} \mathrm{C}$ for 30 seconds, and $72^{\circ} \mathrm{C}$ for 45 seconds, followed by 1 cycle at $72^{\circ} \mathrm{C}$ for 10 minutes.

Animal studies. All aspects of animal care and experimentation performed in this study were approved by the Institutional Animal Care and Use Committee of the Beth Israel Deaconess Medical Center and Harvard Medical School (Boston, Massachusetts, USA). Animals were maintained on a 12-hour light/12-hour dark schedule (lights on at 0600) and were fed laboratory chow and water ad libitum. Glucose tolerance tests (GTTs) were performed in awake mice after a 12-hour fast. Blood was obtained from the tail vein and assayed for glucose at $0,10,20,30,60$, and 120 minutes after intraperitoneal injection of glucose $(1 \mathrm{mg} /$ gram body weight). Blood for insulin, FFAs, lactate, and $\beta$-hydroxybutyrate was obtained by tail-vein bleed from fed mice or from mice that were fasted for 12 hours.

Metabolite assays. Blood glucose was measured with a ONE TOUCH II glucose meter (Lifescan Inc., Milpitas, California, USA). Plasma insulin was measured with the Rat Insulin ELISA kit (Crystal Chem Inc., Chicago, Illinois, USA) using rat standards. Plasma-free fatty acids were measured using the kit from Amano

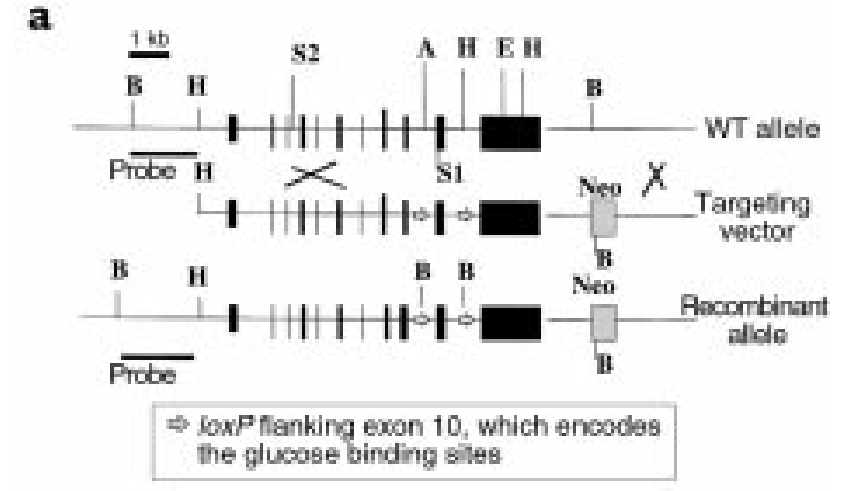

b

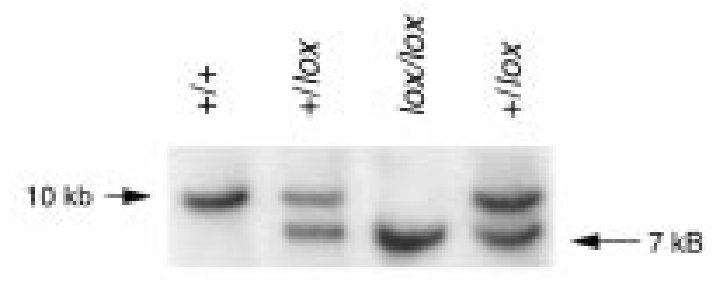

C

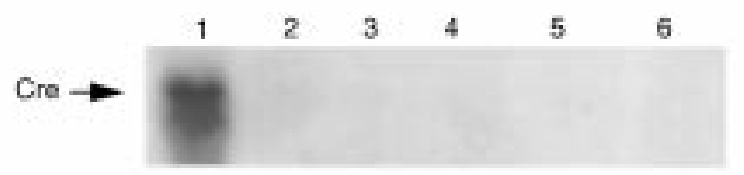

\section{Figure 1}

Transgenic construct, gene targeting, and cardiac specificity of cre expression. (a) Targeting construct used to generate GLUT4 loxP mice. $\mathrm{B}$ represents $\mathrm{Bam} \mathrm{HI}$ restriction sites used in Southern blotting to identify targeted and wild-type alleles using the $5^{\prime}$ probe as shown. Other restriction sites shown: A, Accl; E, EcoRI; H, HindIII; S1, Sacl; S2, Sacll. Neo, neomycin selection marker. (b) Representative Southern blot revealing wild-type and targeted alleles in mice. + represents the wildtype allele (10 kb) and lox represents the loxP-containing allele (7 kb). (c) Northern blot of $15 \mu \mathrm{g}$ of total RNA obtained from tissues of a cre transgenic mouse and probed with the cDNA for cre recombinase. Cre expression is cardiac-specific. 1, heart; 2, skeletal muscle; 3 , brown adipose tissue; 4 , white adipose tissue; 5 , liver; 6 , brain.

Enzyme USA Co. Ltd. (Troy, Virginia, USA), with oleic acid as the standard. Plasma lactate and $\beta$-hydroxybutyrate were measured using colorimetric enzymatic kits from Sigma Chemical Co. (St. Louis, Missouri, USA).

Immunoblots. Immunoblots were performed on postnuclear membranes prepared from cardiac muscle, hind limb skeletal muscle (gastrocnemius and soleus combined), and adipose tissue as described previously (36). Forty micrograms of membrane protein for GLUT4 immunoblots and $60 \mu \mathrm{g}$ for GLUT1 immunoblots were resolved by SDS-PAGE and then transferred to nitrocellulose membranes. More protein was loaded in the GLUT1 immunoblots in order to obtain an adequate GLUT1 signal. Immunoblotting was performed using antisera to the carboxyl terminus (gift of $\mathrm{H}$. Haspel) and amino terminus (gift of G. Gould) of GLUT4, and antisera to the carboxyl terminus of GLUT1 (gift of B. Thorens) and GLUT3 (gift of I. Simpson).

RNA analysis. RNA was extracted from tissue 


\section{Figure 2}

Glucose transporter expression. (a) Representative GLUT4 immunoblots of postnuclear membranes of cardiac muscle obtained from female (F) and male (M) wild-type $(+/+)$ and heartselective GLUT4-ablated ( $\mathrm{G}_{4 \mathrm{H}^{-/}}$; cre lox/lox) mice (left) and female mice of other genotypes: loxP homozygotes (lox/lox) and loxP heterozygotes $(+/$ lox $)$ without cre (right). Similar data exist for males. (b) Representative GLUT1 immunoblots of postnuclear membranes of cardiac muscle from female $\mathrm{G}_{4} \mathrm{H}^{-/-}$(cre lox/lox) mice, loxP homozygotic (lox/lox) mice, heterozygotic (+/lox) mice, and wild-type $(+/+)$ mice. Similar data exist for males. (c) Densitometric analysis of GLUT1 immunoblots obtained from male and female $\mathrm{G} 4 \mathrm{H}^{-/-}$mice and their wild-type controls (aged 18-21 weeks). GLUT1 densities are normalized to 1 for both males and females. Males: wild-type, $n=19 ; \mathrm{G}_{4 \mathrm{H}^{-/-}}, n=7$. Females: wild-type, $n=6 ; \mathrm{G}_{4} \mathrm{H}^{-/-}, n=6 .{ }^{*} P<0.001$ vs. wild-type controls (2-tailed $t$ test). (d) Representative GLUT4 immunoblots (from 5 mice of each genotype) demonstrating the preservation of GLUT4 expression in postnuclear membranes of skeletal muscle of $\mathrm{G}_{4} \mathrm{H}^{-/-}$(cre lox/lox) mice and normal expression of GLUT4 in loxP homozygotes without cre (lox/lox). (e) Representative GLUT4 immunoblots (from 17 mice of each genotype) of postnuclear membranes from white adipose tissue of wild-type $(+/+)$, loxP homozygotic (lox/lox), and $\mathrm{G} 4 \mathrm{H}^{-1-}$ (cre lox/lox) male and female mice. Each panel represents a separate immunoblot. The third panel shows that there is no further change in GLUT4 content in $\mathrm{G}_{4} \mathrm{H}^{-/-}$(cre lox/lox) mice compared with loxP homozygous (lox/lox) mice.

homogenates into a phenol and guanidinium thiocyanate solution (RNA Stat-60 reagent from Tel-Test Inc., Friendswood, Texas, USA) and was recovered by isopropanol precipitation. Samples were resolved on a $1.2 \%$ formaldehyde agarose gel and then transferred to a nylon membrane. For studies of cre expression, the blots were hybridized to an $\alpha_{-}{ }^{32} \mathrm{P}$-labeled cDNA probe corresponding to the first $400 \mathrm{bp}$ of cre. The probes (gifts of S. Izumo) used for analysis of atrial natriuretic peptide (ANP) and brain natriuretic peptide (BNP) expression were a 250-bp ApaI-SacI fragment of the mouse ANP gene and a 230-bp EcoRI-XhoI fragment of the mouse $B N P$ gene. All blots were hybridized under high-stringency conditions.

Histology. Hearts were rapidly excised from mice after sacrifice with $\mathrm{CO}_{2}$. The hearts were dissected to expose the ventricular septum and then preserved in buffered formaldehyde. The tissues were embedded in paraffin and $5-\mu \mathrm{m}$ sections were cut. Sections were stained with hematoxylin and eosin to assess myofiber architecture, and with trichrome to examine for interstitial fibrosis. For quantitative histomorphometry, sections were stained with periodic acid-Schiff. Five separate regions per slide in which the myocytes were predominantly represented in cross-sectional orientation were photomicrographed at $\times 40$. Kodachrome micrographs were coded and optically digitized. Myofiber outlines were traced using computer-assisted morphometry (37). Myocyte areas were determined using quantitative image analysis (SigmaScan Pro; Jandel Scientific Software, San Rafael, California, USA). Myofibers of which the entire outline could be determined were traced and a

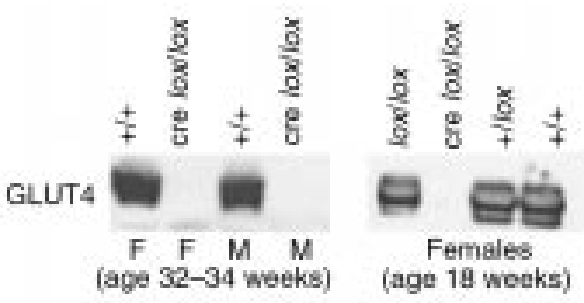

b

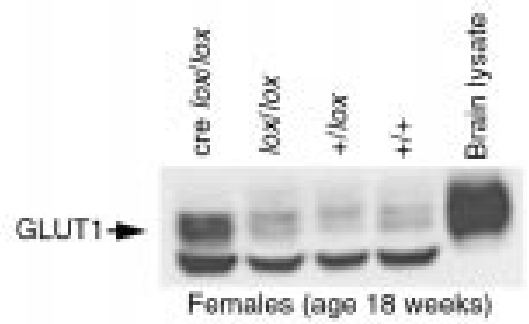

c

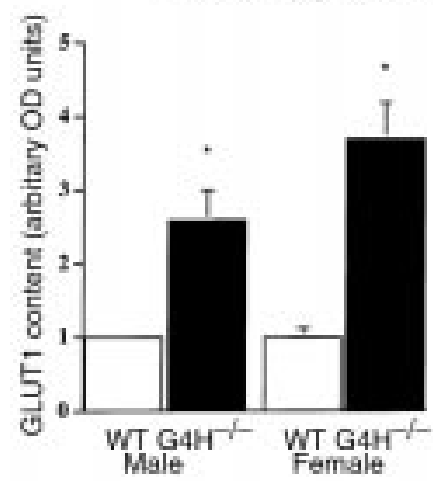

d

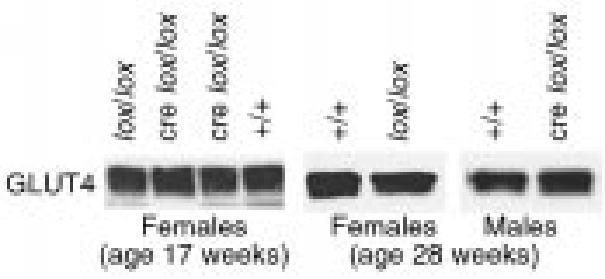

e

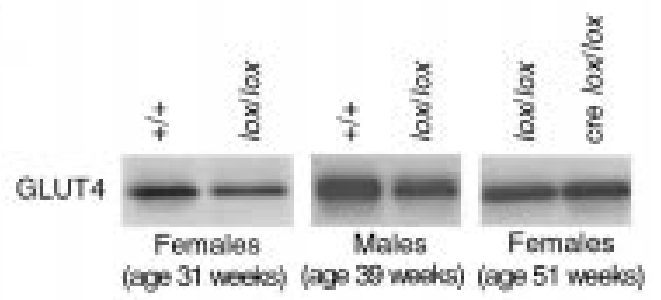

recorded in a blinded fashion. Each micrograph yielded an average of 7 suitable myofibers for analysis. A minimum of 25 myofibers per heart was examined in this way. Mean myofiber area was expressed in square pixels. Isolated perfused heart preparation. Mice were heparinized (100 U given intraperitoneally) 30 minutes before being sacrificed by cervical dislocation. The heart was excised and then arrested in ice-cold buffer. It was then connected via the aorta to the perfusion cannula. Retrograde perfusion was maintained at a constant pressure of $80 \mathrm{mmHg}$ at $37^{\circ} \mathrm{C}$. A short polyethylene drain was placed through the apex of the left ventricle to drain the effluent from the thebesian veins. Coronary flow rate was monitored by collecting coro- 

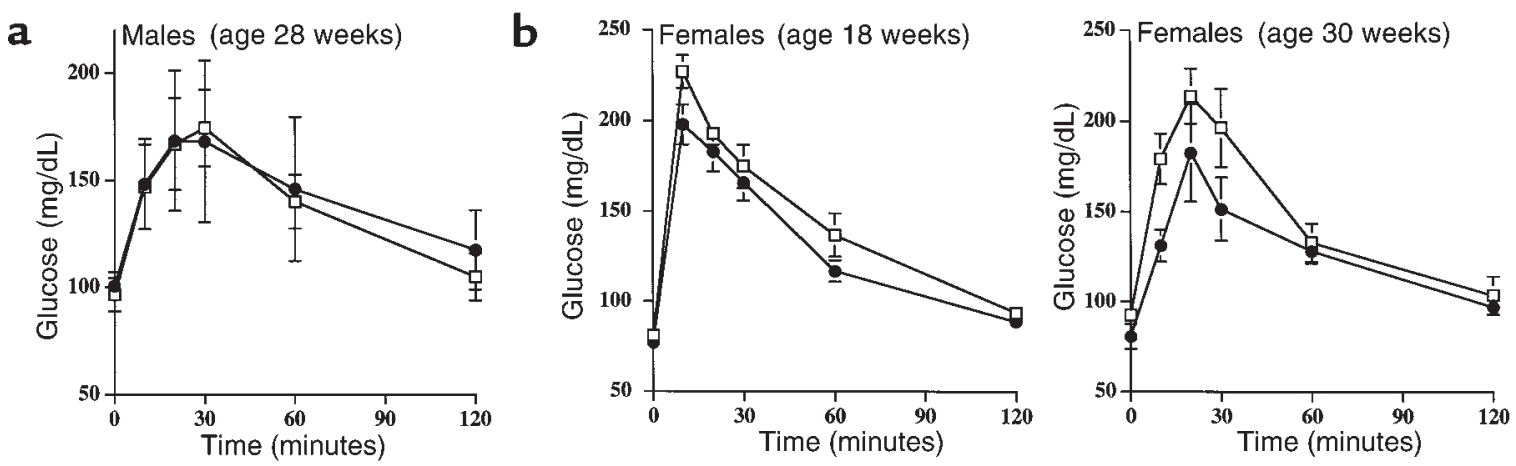

\begin{abstract}
Figure 3
GTTs in awake $\mathrm{G}_{4} \mathrm{H}^{-/-}$mice (squares) and age-matched littermate controls (circles). Blood glucose concentrations at 0, 10, 20, 30, 60, and 120 minutes after intraperitoneal injection of glucose ( $1 \mathrm{mg} / \mathrm{gram}$ body weight). (a) Mean $\pm \mathrm{SEM}$ for 28 -week-old males ( $6 \mathrm{G} 4 \mathrm{H}^{-/}-$

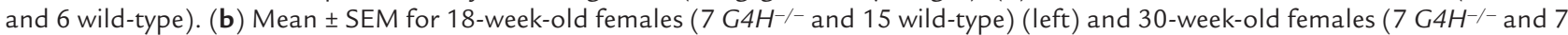
wild-type) (right). There are no statistical differences between wild-type and $\mathrm{G}_{4} \mathrm{H}^{-/}-\mathrm{GTT}$ s by repeated-measures ANOVA.
\end{abstract}

nary sinus effluent. (Thebesian vein drainage is assumed to be included in the measurement of coronary flow.) Hearts were perfused with modified KrebsHenseleit buffer containing $118 \mathrm{mM} \mathrm{NaCl}, 25 \mathrm{mM}$ $\mathrm{NaHCO}_{3}, 4.1 \mathrm{mM} \mathrm{KCl}, 2.5 \mathrm{mM} \mathrm{CaCl}_{2}, 1.2 \mathrm{mM} \mathrm{MgSO}_{4}$, $0.5 \mathrm{mM}$ EDTA, $1.2 \mathrm{mM} \mathrm{KH}_{2} \mathrm{PO}_{4}, 5 \mathrm{mM}$ acetate, $2 \mathrm{mM}$ glucose, and $0.5 \mathrm{mM}$ pyruvate. This buffer supplied pyruvate and acetate as substrates so that oxidative metabolism in the hearts could be maintained despite differences in glucose uptake (1). A concentration of 2 $\mathrm{mM}$ glucose was used in order to match the concentration of 2-deoxyglucose (2-DG) used in the glucose uptake assay (see below). The perfusate was equilibrated with $95 \% \mathrm{O}_{2}$ and $5 \% \mathrm{CO}_{2}$ at a $\mathrm{pH}$ of 7.4. The temperature was maintained at $37^{\circ} \mathrm{C}$ with a water jacket. A water-filled balloon was inserted into the left ventricle for recording ventricular pressure and heart rate. Balloon volume was adjusted to achieve an end-diastolic pressure of 5-10 $\mathrm{mmHg}$. Isovolumic contractile function was estimated by the product of left ventricular (LV) developed pressure and heart rate (rate pressure product; RPP). To test the response of $\mathrm{G}_{4} \mathrm{H}^{-/}$hearts to inotropic stimulation, isoproterenol was infused in a subset of hearts ( $n=5$ for each group) at final concentrations of $0.5 \mathrm{nM}$ and $10 \mathrm{nM}$ (in order to ascertain submaximal and peak responses). Because there was no difference between the sexes in contractile performance, data from males and females were combined in the isoproterenol studies.

Assessment of glucose uptake rate in isolated mouse hearts. The rate of glucose entry was measured in isolated perfused hearts by phosphorous-31 $\left.{ }^{31} \mathrm{P}\right)$ nuclear magnetic resonance (NMR) spectroscopy using the glucose analogue 2-DG. The isolated perfused heart was placed in a $10-\mathrm{mm}$ NMR sample tube and inserted into a ${ }^{1} \mathrm{H} /{ }^{31} \mathrm{P}$ double-tuned probe situated in a 9.4-Tesla superconducting magnet with a bore of $89 \mathrm{~cm}$. After stabilization, the heart was perfused with a buffer in which $2 \mathrm{mM} 2$ DG was substituted for glucose. Upon entering the cell,
2-DG is phosphorylated by hexokinase to 2-DG phosphate (2-DG-P), which produces an easily detectable peak in ${ }^{31} \mathrm{P}$ NMR spectroscopy. The area of this peak is proportional to the amount of accumulated 2-DG-P. Transport rate was assessed by calculating the slope of the time-dependent increase in 2-DG-P. Although phosphorylation of 2-DG leads to decreases in concentrations of phosphocreatine and eventually of ATP, the perfusion protocol was designed to ensure the linearity of 2-DG-P accumulation with time throughout the procedure for the concentration of 2-DG used. Thus accurate measurements of transport rate can be obtained both at baseline and during insulin stimulation. The modified protocol includes supplying acetate and pyruvate to support oxidative phosphorylation, supplying $\mathrm{KH}_{2} \mathrm{PO}_{4}$ to replenish the intracellular inorganic phosphate pool, and infusing insulin for only a short period of time (16 minutes). The hearts were initially perfused for $24 \mathrm{~min}$ utes with an insulin-free buffer, and $6^{31} \mathrm{P}$ spectra - each obtained by signal averaging of 104 free induction decays - were collected. Insulin $(2 \mathrm{mU} / \mathrm{mL})$ was then added to the perfusate and another 4 spectra were collected to assess the maximal rate of insulin-stimulated glucose transport. Each spectrum was collected using a $60^{\circ}$ flip angle, 15 -microsecond pulse, 2.14-second delay, $6,000 \mathrm{~Hz}$ sweep width, and 2048 data points using a GE400 Omega NMR spectrometer (Bruker Instruments, Freemont, California, USA). Spectra were analyzed using $20-\mathrm{Hz}$ exponential multiplication and zero- and firstorder phase corrections. The resonance peak area for 2DG-P was fitted by Lorentzian line shapes using NMR1 software (New Methods Research Inc., Syracuse, New York, USA). By comparing the peak areas of fully relaxed spectra (recycle time: 15 seconds) and partially saturated spectra (recycle time: 2.14 seconds), the correction factor for saturation was calculated for 2-DG-P (1.35). The 2-DG peak area was normalized to heart weight and expressed in arbitrary area units.

Statistical analysis. Data are expressed as mean \pm SEM. 

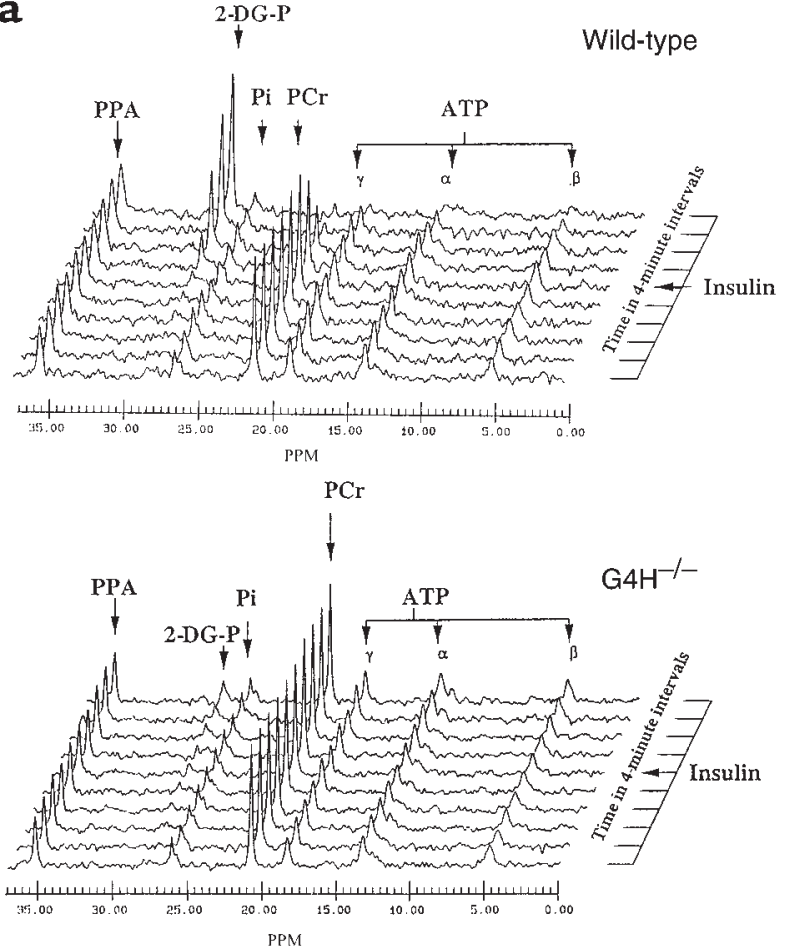

b

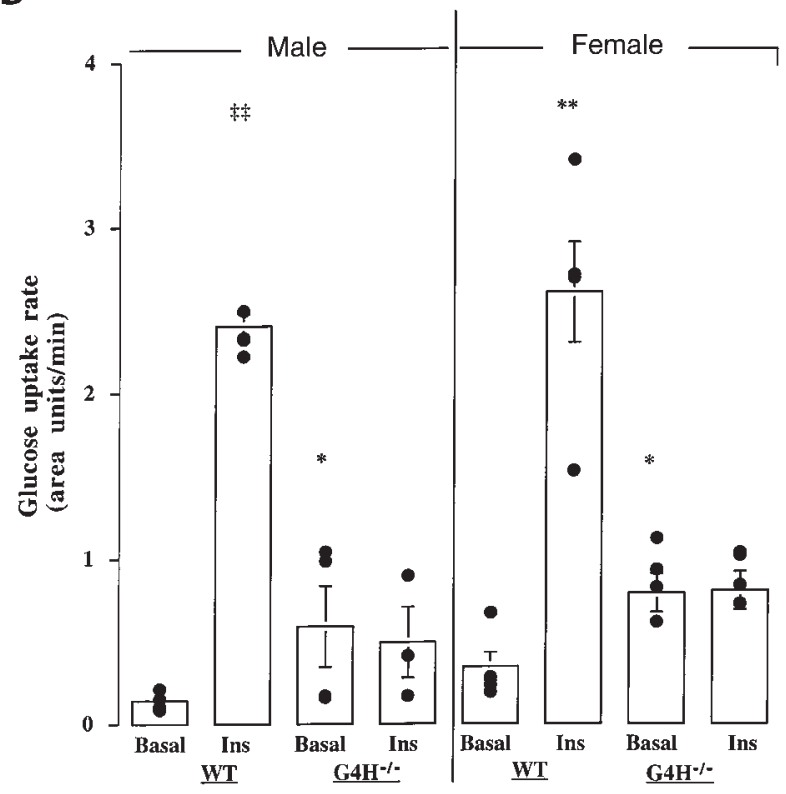

Figure 4

Evidence for impaired GLUT4-mediated glucose uptake in GLUT4-ablated hearts. (a) Representative ${ }^{31} \mathrm{P}$ NMR spectra in wild-type and $\mathrm{G} 4 \mathrm{H}^{-/-}$hearts, illustrating absence of insulin-mediated augmentation of 2-DG-P accumulation in GLUT4-deficient hearts. The decline in phosphocreatine (PCr) after insulin stimulation in wild-type mice probably represents transfer of phosphates to 2-DG-P. PPA, phenylphosphonic acid standard; $\mathrm{Pi}$, inorganic phosphate. $\gamma, \alpha$, and $\beta$ represent the 3 phosphates on adenosine in ATP. (b) Basal and insulin-stimulated 2-DG uptake in wild-type and $\mathrm{G}_{4} \mathrm{H}^{-/-}$mice. Bars represent mean $\pm \mathrm{SEM}$; individual data points are illustrated by the closed circles. Number of animals in each group: Wild-type males: basal, $n=5$; insulin-stimulated (Ins), $n=5$. G4H-1- males: basal, $n=4$; insulin-stimulated, $n=3$. Wild-type females: basal, $n=5$; insulin-stimulated, $n=5 . G 4 H^{-1-}$ females: basal, $n=5$; insulin-stimulated, $n=5$. ${ }^{*} P<0.05$ vs. wild-type basal of either sex (ANOVA). $\ddagger \ddagger P<0.0001,{ }^{*} P<0.004$ vs. wild-type basal of the same sex (paired 2 -tailed $t$ test).

When analyzing measurements obtained in wild-type and $\mathrm{G}_{4} \mathrm{H}^{-/-}$mice of both sexes, differences were analyzed by ANOVA; significance was assessed at the 95\% and $99 \%$ significance levels by the Fisher PLSD statistical test. Differences between basal and insulin-stimulated cardiac glucose uptake within a given sex were assessed by the paired 2-tailed $t$ test. Data involving more than 2 repeated measures (GTTs and contractile performance in isolated perfused hearts) were assessed by repeated-measures ANOVA. Difference in myocyte cross-sectional area was assessed with the unpaired 2 tailed $t$ test. Non-normally distributed data (ANP and BNP expression levels) were compared using the MannWhitney $U$ test. Statistical calculations were performed using the StatView 512+ software package (BrainPower Inc., Calabasas, California, USA.)

\section{Results}

Generation of mice with cardiac-selective GLUT4 ablation $\left(\mathrm{G}_{4} \mathrm{H}^{-/-}\right.$mice). Three independent targeted clones were obtained after electroporation of the GLUT4 loxP vector into embryonic stem cells. Two clones, each containing 1 wild-type GLUT4 allele and 1 modified loxP allele, were expanded and injected into the blastocysts of C57BL6 mice. Chimeric mice were generated from both clones, and 2 independent lines of mice bearing 1 normal allele and 1 loxP-containing GLUT4 allele $(+/ l o x)$ were derived from these chimeric mice (Figure $1 b)$. An FVB background was used for $\alpha$-MHC Cre transgenic mice (Figure 1c). Cre transgenic mice (wildtype for the GLUT4 allele) were crossed with GLUT4 $+/$ lox heterozygotes. Some of the offspring inherited the transgene and were heterozygous for the modified loxP allele $\left(\mathrm{cre}^{+} / \mathrm{lox}\right)$. Mice with cardiac-specific GLUT4 ablation $\left(\mathrm{G} 4 \mathrm{H}^{--}\right)$were derived by crossing cre $+/$lox mice with GLUT4 loxP heterozygotes. This breeding paradigm resulted in 6 genotypes: $\mathrm{cre}^{+/+}$, cre $+/$lox, and cre lox/lox (all with cre); and $+/+,+/ l o x$, and lox/lox (all without cre). $\mathrm{G} \mathrm{H}^{-/-}$mice have the genotype cre lox/lox and were born with the expected mendelian frequency, indicating that the absence of cardiac GLUT4 did not cause embryonic lethality. $\mathrm{G} \mathrm{H}^{-/-}$mice exhibited normal life span. Most mice were sacrificed for studies by 12 months of age. In an analysis of a cohort of 78 mice (39 wild-type and $39 \mathrm{G}_{4} \mathrm{H}^{-/-}$), all animals were alive at 6 months of age. Sixteen wild-type mice and $16 \mathrm{G}_{4} \mathrm{H}^{-1}$ mice were sacrificed at 7 months. At 9 months, all of the 23 remaining $\mathrm{G}_{4} \mathrm{H}^{-/-}$mice were still alive. Twenty of these mice were sacrificed between 9 and 12 months of age. The remaining 3 mice survived for longer than 18 
months, implying that there was no reduction in the longevity of $\mathrm{G} 4 \mathrm{H}^{-/-}$mice. Growth retardation was not observed in mice of up to 6 months of age. A variable reduction in body weight was seen in older male $\mathrm{G}_{4} \mathrm{H}^{-1}$ mice, but not in female mice (see Table 2b).

Glucose transporter expression. $G 4 H^{-1-}$ mice had no GLUT4 immunoreactivity in the heart, in contrast to wild-type or GLUT4 loxP homozygotes (without cre expression) (Figure 2a). We were unable to detect any GLUT4 protein in the hearts of $\mathrm{G}_{4} \mathrm{H}^{-/-}$mice with antibodies to either the carboxyl or amino terminus of GLUT4. Cardiac GLUT1 content was upregulated 2.6fold ( \pm 0.4 -fold) in male $\mathrm{G}_{4 H^{-/-}}$mice and 3.7-fold $( \pm 0.5$ fold) in female $\mathrm{G}_{4} \mathrm{H}^{-/-}$mice $(P<0.001)$, compared with their respective wild-type controls and with GLUT4 loxP homozygotes (without cre) (Figures 2, b and c). There was no upregulation of GLUT3 in the heart (data not shown). Skeletal muscle GLUT4 content was similar in wild-type mice, loxP homozygotic mice, and $\mathrm{G} \mathrm{H}^{-/-}$ mice (assessed by densitometry of skeletal muscle GLUT4 immunoblots from 5 mice of each genotype), indicating that the modified GLUT4 loxP gene was normally expressed in skeletal muscle and that there was no aberrant cre expression in skeletal muscle (Figure $2 \mathrm{~d}$ ). In loxP homozygous mice, GLUT4 protein content was assessed by laser densitometry of immunoblots of white adipose tissue membrane samples from 17 lox/lox mice and 17 wild-type (+/+) mice of various ages. The mean GLUT4 content of white adipose tissue from lox/lox mice was $52 \pm 11 \%$ of wild-type control levels. The variable decrease in adipose tissue GLUT4 content indicates that the loxP modification of the GLUT4 gene resulted in lower expression levels in adipose tissue (Figure 2e). Adipose tissue GLUT4 content in $\mathrm{G} 4 \mathrm{H}^{-/-}$ mice was similar to that in loxP homozygotes without cre (Figure 2e). To control for this partial reduction of GLUT4 in adipose tissue, homozygous loxP mice without cre were used as an additional control group for the studies of in vivo metabolism.

Metabolic profiles. GTTs were performed on age- and sex-matched $\mathrm{G} \mathrm{H}^{-/-}$mice and control mice between 28 and 30 weeks of age (Figure 3, a and b). Glucose tolerance was similar in male $\mathrm{G}_{4} \mathrm{H}^{-/-}$mice and littermate controls (wild-type for the GLUT4 allele) (Figure 3a). There was a suggestion of mild impairment in glucose tolerance in female $\mathrm{G}_{4} \mathrm{H}^{-/-}$mice at 30 weeks (Figure $3 \mathrm{~b}$, right), although the 2 curves were not statistically different by repeated-measures ANOVA. GTTs were then performed on a younger cohort (age 18 weeks), and the resulting curves were completely overlapping (Figure $3 \mathrm{~b}$, left). There was no increase in fed or fasted insulin concentrations in $\mathrm{G}_{4} \mathrm{H}^{-/-}$mice of either sex (Table 1). Fasted and fed concentrations of the cardiac metabolic substrates $\beta$-hydroxybutyrate, FFAs, and lactate in $\mathrm{G} \mathrm{H}^{-/-}$mice were similar to levels in controls (Table 1). There were no differences in the metabolic profiles or GTTs of loxP homozygotes (without cre) when compared with wild-type mice (data not shown).

Cardiac glucose uptake. Basal and insulin-stimulated cardiac glucose uptake were assessed in isolated perfused hearts by measuring the accumulation of 2-DG$\mathrm{P}$ using ${ }^{31} \mathrm{P}$ NMR spectroscopy (Figure 4a). The decline in the phosphocreatine peak after insulin stimulation in wild-type mice probably represents transfer of phosphates to 2-DG-P (Figure 4a). There were striking differences in both basal and insulin-stimulated glucose

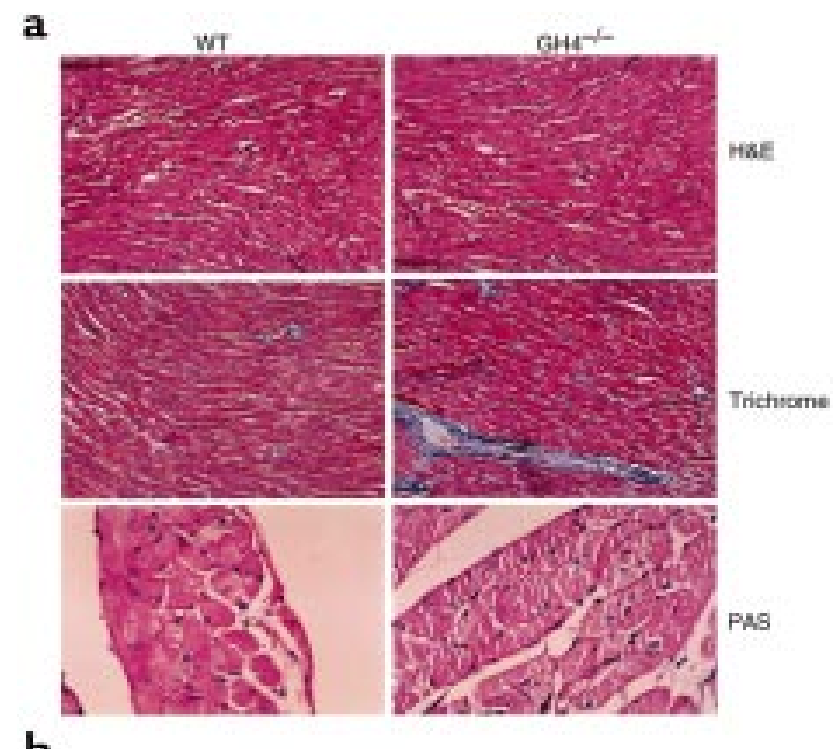

b

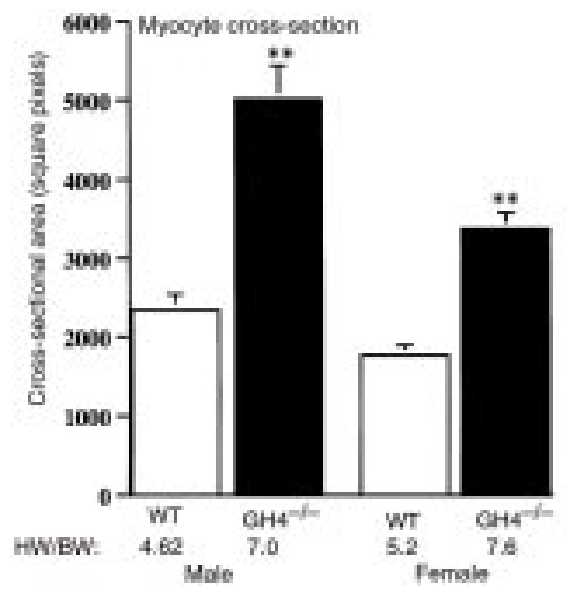

\section{Figure 5}

Cardiac histology. (a) Representative transverse sections of left ventricle stained with hematoxylin and eosin (H\&E) (top row) and trichrome (middle row) of a wild-type and a $\mathrm{G}_{4} \mathrm{H}^{-1}$ - female mouse (aged 30 weeks) illustrating the absence of gross morphological abnormalities of myocyte architecture and the absence of any increase in interstitial collagen. $\times 600$ (original magnification). Representative periodic acid-Schiff (PAS) cross-sections (bottom row) taken from the left ventricle of a female $\mathrm{G}_{4} \mathrm{H}^{-/-}$mouse and an agematched control (aged 20 weeks), illustrating the sections used for quantitative histomorphometry. Data are similar for males (not shown). (b) Quantitative histomorphometry of male and female $\mathrm{G} 4 \mathrm{H}^{-/-}$and wild-type hearts (a single heart is represented for each). Heart weight to body weight ratios (HW/BW) are shown beneath each bar. Males: $n=28$ cross-sections for wild-type mice and 27 cross-sections for $\mathrm{G}_{4} \mathrm{H}^{-/-}$mice. Females: $n=37$ cross-sections for wild-type and 43 cross-sections for $G 4 H^{-/-}$. ${ }^{*} P<0.0001$ vs. wildtype of the same sex (unpaired 2-tailed $t$ test). 
Figure 6

$A N P$ and $B N P$ gene expression. (a) Northern blot showing changes in the expression of ANP and BNP mRNA in wild-type (first 5 lanes) and $\mathrm{G}_{4 \mathrm{H}^{-/-}}$mice (last 4 lanes). Data shown are from male mice 13-14 weeks of age. Thirty micrograms of total RNA was loaded in each lane. (b) Densitometric analysis of Northern blot data after correcting for loading with cyclophyllin. Note differences in the scales ( $y$ axis) of the ANP and BNP plots. $P=0.016$ for wild-type BNP vs. $G 4 H^{-1-}$ BNP expression. $P=$ 0.112 for wild-type ANP vs. $\mathrm{G}_{4} \mathrm{H}^{-/-}$ ANP expression (Mann-Whitney $U$ test 2-tailed probabilities). Wild-

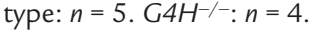

\section{a}

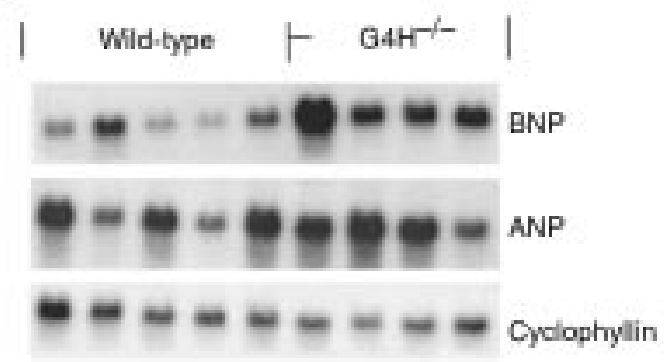

b
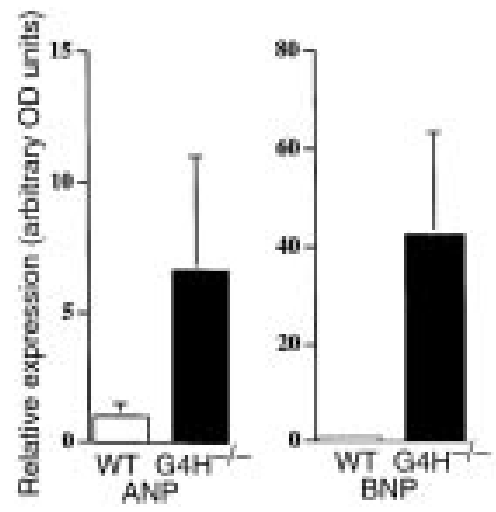

Cardiac weights and histology. Heart weights were obtained before histological analysis on male and female mice (average age 19 weeks and 21 weeks, respectively) (Table 2a). The hearts of $\mathrm{G} \mathrm{H}^{-/-}$mice were significantly heavier (by $38 \%$ in males and $35 \%$ in females) than those of their respective wild-type controls. The heart weight to body weight ratio was significantly higher in $\mathrm{G} \mathrm{H}^{-/-}$males (43\% higher than wild-type; $P<0.01)$ and tended to be higher in $\mathrm{G}_{4} \mathrm{H}^{-/}$ females (25\% higher than wildtype). Wet and dry heart weights were also obtained from mice (average age 35-39 weeks) that underwent glucose uptake measurements (Table 2b). As was observed in the younger cohort, heart weights were higher in the G4H $H^{-/-}$mice, and the difference achieved statistical significance in

uptake in $\mathrm{G} 4 \mathrm{H}^{-/-}$mice when compared with wild-type controls (Figure 4b). Insulin-mediated glucose uptake was abolished in $\mathrm{G}_{4} \mathrm{H}^{-/-}$hearts, whereas insulin increased glucose uptake above basal levels by 17 -fold $(P<0.0001)$ in male wild-type mice, and by 8 -fold $(P<$ 0.004 ) in female wild-type mice. Basal glucose uptake in $\mathrm{G}_{4} \mathrm{H}^{-/-}$male hearts was $0.59 \pm 0.25$ area units $/ \mathrm{min}$, which is 4-fold higher than the uptake of $0.142 \pm 0.022$ area units/min in male wild-type hearts $(P<0.05)$. The basal uptake in female $\mathrm{G}_{4 H^{-/}}$mice $(0.79 \pm 0.12$ area units/min) was 2 -fold higher than in female controls $(0.344 \pm 0.090$ area units $/ \mathrm{min})(P<0.05)$. The increase in basal glucose uptake in $\mathrm{G} \mathrm{H}^{-/-}$mice was similar in magnitude to the increase in GLUT1 expression. Interestingly, female wild-type mice tended to have higher basal glucose uptake than did male wild-type mice, and this difference between sexes was lost in $\mathrm{G}_{4} \mathrm{H}^{-/-}$mice. both sexes. In absolute terms, heart weights (wet and dry, respectively) were increased by $16 \%$ and $25 \%$ in $\mathrm{G}_{4} \mathrm{H}^{-/-}$males vs. wild-type males, and by $35 \%$ and $42 \%$ in $G 4 H^{-/-}$females. When corrected for body weight, the changes were more marked in male $\mathrm{G}_{4} \mathrm{H}^{-/-}$mice $(39 \%$ and $45 \%$ for wet and dry heart weight to body weight ratios, respectively) than in $\mathrm{G} \mathrm{H}^{-/-}$females $(17 \%$ and $23 \%$, respectively). Histological examination of hematoxylin and eosin- and trichrome-stained sections was performed on the hearts of mice at 20,30, and 50 weeks of age. In all age groups, there were no gross morphological abnormalities of myocyte architecture, and analysis of trichrome-stained sections revealed no increase in interstitial collagen compared with controls (Figure 5a). Myocyte cross-sectional areas were measured using quantitative image analysis on sections from 20-week-old mice stained with periodic acid-Schiff.

Table 1

Serum insulin and metabolite concentrations

\begin{tabular}{|c|c|c|c|c|c|c|c|c|}
\hline & \multicolumn{4}{|c|}{ FED } & \multicolumn{4}{|c|}{ FASTED } \\
\hline & \multicolumn{2}{|c|}{ Male } & \multicolumn{2}{|c|}{ Female } & \multicolumn{2}{|c|}{ Male } & \multicolumn{2}{|c|}{ Female } \\
\hline & $\mathrm{G}_{4} \mathrm{H}^{-/-}$ & WT & $\mathrm{G} 4 \mathrm{H}^{-/-}$ & WT & $\mathrm{G} 4 \mathrm{H}^{-/-}$ & WT & $\mathrm{G} 4 \mathrm{H}^{-/-}$ & WT \\
\hline Insulin (ng/mL) & $\begin{array}{c}2.09 \pm 0.40 \\
(11)\end{array}$ & $\begin{array}{c}2.25 \pm 0.40 \\
(19)\end{array}$ & $\begin{array}{c}1.06 \pm 0.16 \\
(18)\end{array}$ & $\begin{array}{c}1.17 \pm 0.17 \\
(19)\end{array}$ & $\begin{array}{c}0.61 \pm 0.13 \\
(6)\end{array}$ & $\begin{array}{c}0.43 \pm 0.08 \\
(12)\end{array}$ & $\begin{array}{c}0.62 \pm 0.09 \\
(17)\end{array}$ & $\begin{array}{c}0.62 \pm 0.10 \\
(17)\end{array}$ \\
\hline $\mathrm{FFAs}(\mathrm{mmol} / \mathrm{L})$ & $\begin{array}{c}0.57 \pm 0.11 \\
(5)\end{array}$ & $\begin{array}{c}0.64 \pm 0.06 \\
(15)\end{array}$ & $\begin{array}{c}0.45 \pm 0.08 \\
(9)\end{array}$ & $\begin{array}{c}0.53 \pm 0.04 \\
(17)\end{array}$ & $\begin{array}{c}1.45 \pm 0.15 \\
(5)\end{array}$ & $\begin{array}{c}1.19 \pm 0.06 \\
(15)\end{array}$ & $\begin{array}{c}1.18 \pm 0.12 \\
(9)\end{array}$ & $\begin{array}{c}0.97 \pm 0.07 \\
(15)\end{array}$ \\
\hline$\beta \mathrm{OHB}(\mathrm{mg} / \mathrm{dL})$ & $\begin{array}{c}1.89 \pm 0.70 \\
(5)\end{array}$ & $\begin{array}{c}2.42 \pm 0.52 \\
(12)\end{array}$ & $\begin{array}{c}1.88 \pm 0.44 \\
(9)\end{array}$ & $\begin{array}{c}1.65 \pm 0.36 \\
(14)\end{array}$ & $\begin{array}{c}8.52 \pm 1.54 \\
(12)\end{array}$ & $\begin{array}{c}9.53 \pm 1.69 \\
(12)\end{array}$ & $\begin{array}{c}9.30 \pm 2.1 \\
(9)\end{array}$ & $\begin{array}{c}9.51 \pm 1.56 \\
(14)\end{array}$ \\
\hline Lactate (mg/dL) & $\begin{array}{c}80 \pm 9 \\
(5)\end{array}$ & $\begin{array}{c}70 \pm 6 \\
(15)\end{array}$ & $\begin{array}{c}52 \pm 6 \\
(9)\end{array}$ & $\begin{array}{c}61 \pm 3 \\
(18)\end{array}$ & $\begin{array}{c}109 \pm 19 \\
(5)\end{array}$ & $\begin{array}{c}104 \pm 13 \\
(15)\end{array}$ & $\begin{array}{c}80 \pm 11 \\
(9)\end{array}$ & $\begin{array}{c}112 \pm 9 \\
(16)\end{array}$ \\
\hline
\end{tabular}

WT, wild-type controls; $\beta \mathrm{OHB}, \beta$-hydroxybutyrate. Data are presented as mean \pm SEM. Number of mice is in parentheses. Serum insulin was obtained in animals between 12 and 19 weeks of age. The other metabolites were obtained in mice between 22 and 32 weeks of age. There were no differences in the mean ages of wild-type and $\mathrm{G}_{4} \mathrm{H}^{--}$male and female mice in each group. There were no significant differences in metabolite concentrations (fasted or fed) between wild-type and $\mathrm{G}_{4 \mathrm{H}^{-/-}}$mice of either sex by ANOVA. 
Table 2

Heart weights and body weights

\begin{tabular}{|c|c|c|c|c|c|c|c|}
\hline (a) & $n$ & Age (weeks) & $\mathrm{BW}(\mathrm{g})$ & Wet HW (mg) & Wet HW/BW & & \\
\hline $\begin{array}{l}\mathrm{G} 4 \mathrm{H}^{-1-} \text { male } \\
\mathrm{WT} \text { male } \\
\mathrm{G} 4 \mathrm{H}^{-/-} \text {female } \\
\text { WT female }\end{array}$ & $\begin{array}{l}4 \\
4 \\
4 \\
4\end{array}$ & $\begin{array}{l}18.5 \pm 1.3 \\
18.5 \pm 1.3 \\
21.3 \pm 1.2 \\
21.3 \pm 1.2\end{array}$ & $\begin{array}{l}27.5 \pm 2.1 \\
28.3 \pm 2.1 \\
27.5 \pm 1.9 \\
25.3 \pm 1.3\end{array}$ & $\begin{array}{c}180 \pm 17^{A, C} \\
130 \pm 11 \\
164 \pm 21 \\
121 \pm 6\end{array}$ & $\begin{array}{c}6.527 \pm 0.36^{\mathrm{B}, \mathrm{C}} \\
4.567 \pm 0.06 \\
5.994 \pm 0.7 \mathrm{C} \\
4.793 \pm 0.16\end{array}$ & & \\
\hline (b) & $n$ & Age (weeks) & $\mathrm{BW}(\mathrm{g})$ & Wet HW (mg) & Wet HW/BW & Dry HW (mg) & Dry HW/BW \\
\hline $\begin{array}{l}\mathrm{G} 4 \mathrm{H}^{-/-} \text {male } \\
\mathrm{WT} \text { male } \\
\mathrm{G} 4 \mathrm{H}^{-/-} \text {female } \\
\text { WT female }\end{array}$ & $\begin{array}{l}7 \\
8 \\
6 \\
7\end{array}$ & $\begin{array}{l}39 \pm 4 \\
35 \pm 2 \\
37 \pm 4 \\
35 \pm 3\end{array}$ & $\begin{array}{c}33.0 \pm 1.5^{\mathrm{A}, \mathrm{C}} \\
39.0 \pm 1.8^{\mathrm{D}} \\
32.0 \pm 2.4^{\mathrm{D}} \\
27.4 \pm 1.1\end{array}$ & $\begin{array}{c}252 \pm 12^{\mathrm{A}, \mathrm{D}} \\
215 \pm 11^{\mathrm{D}} \\
215 \pm 10^{\mathrm{B}, \mathrm{E}} \\
159 \pm 7\end{array}$ & $\begin{array}{c}7.64 \pm 0.23^{\mathrm{B}, \mathrm{D}} \\
5.51 \pm 0.17 \\
6.81 \pm 0.27^{\mathrm{B}, \mathrm{D}, \mathrm{E}} \\
5.83 \pm 0.25\end{array}$ & $\begin{array}{c}51.8 \pm 3.1^{A, D} \\
41.3 \pm 3.7^{C} \\
44.3 \pm 2.7^{B} \\
31.0 \pm 2.1\end{array}$ & $\begin{array}{c}1.56 \pm 0.07^{\mathrm{B}, \mathrm{D}} \\
1.05 \pm 0.07 \\
1.41 \pm 0.11^{\mathrm{A}, \mathrm{D}} \\
1.14 \pm 0.07\end{array}$ \\
\hline
\end{tabular}

Heart weights represent the weight of the entire heart. Hearts shown in (a) were fixed for histological analysis, therefore dry weights were not measured. Significance values by ANOVA: ${ }^{A} P<0.05,{ }^{B} P<0.01$ vs. wild-type of same sex; ${ }^{C} P<0.05$, ${ }^{D} P<0.01$ vs. wild-type of opposite sex; ${ }^{E} P<0.05$ vs. $G 4 H^{-1-}$ males. $n$, number of animals; BW, body weight; HW, heart weight.

This analysis was performed to address the question of whether increased cardiac size in transgenic mice was due to increased myocyte size. The heavier hearts have greater myocyte cross-sectional areas (Figure $5 b$ ), supporting the hypothesis that the observed cardiac hypertrophy (evidenced by increased heart weight) is due to myocyte hypertrophy as opposed to increased interstitial content.

Expression of ANP and BNP in the heart. Because increased cardiac expression of the natriuretic peptides ANP and BNP are universal features of cardiac hypertrophy of diverse etiologies $(38,39)$, we examined the expression of the $A N P$ and $B N P$ genes in the ventricles of $\mathrm{G}_{4 H^{-/}}$mice and littermate controls. There was a striking 43-fold increase in $B N P$ gene expression in $\mathrm{G}_{4} \mathrm{H}^{-/-}$mice $(P=$ 0.016 ). Although more variable, $A N P$ expression on average was induced 7 -fold (Figure 6, a and b).

Cardiac contractile function. Table 3 shows baseline measurements in isolated perfused hearts immediately before the 2-DG uptake assay. Heart rate and coronary flow per gram heart weight were similar in all hearts. When LV end-diastolic pressure was set to 5-10 $\mathrm{mmHg}, \mathrm{LV}$ systolic pressure and RPP were indistinguishable between wild-type and $\mathrm{G}_{4} \mathrm{H}^{-/-}$hearts. Figure 7 shows contractile responses to isoproterenol infusion in $\mathrm{G} \mathrm{H}^{-/-}$and control hearts. The responses in $\mathrm{LV}$ developed pressure, LV end-diastolic pressure, heart rate, and rates of contraction and relaxation were similar in both groups.

\section{Discussion}

We used cre-loxP gene targeting to inactivate the GLUT4 gene selectively in the heart. GLUT4 expression was preserved in skeletal muscle, and although the expression of GLUT4 was variably reduced in the adipose tissue of loxp homozygous (lox/lox) mice (without cre expression), in extensive metabolic analyses comparing lox/lox mice with wild-type mice, we found no differences in glucose tolerance, concentration of insulin or metabolic substrates, body weight, or heart weight. We have also measured contractile performance and glucose uptake in a small number of lox/lox hearts and found no difference from wild-type mice. For this reason we compared $\mathrm{G}_{4} \mathrm{H}^{-/-}$mice with wild-type controls. These $G 4 H^{-/-}$mice allow assessment of the physiological role of GLUT4 in the heart in vivo in the absence of metabolic perturbations such as altered substrate supply and hyperinsulinemia, which could potentially confound the interpretation of the cardiac phenotype.

The major finding of this study is that the absence of GLUT4 in the heart results in the development of cardiac hypertrophy with preserved contractile function, and does not impair longevity. Hypertrophy is evidenced by increased cardiac weight, myocyte cross-sectional area, and the induction of $A N P$ and $B N P$ gene expression, and occurs in the absence of changes in the

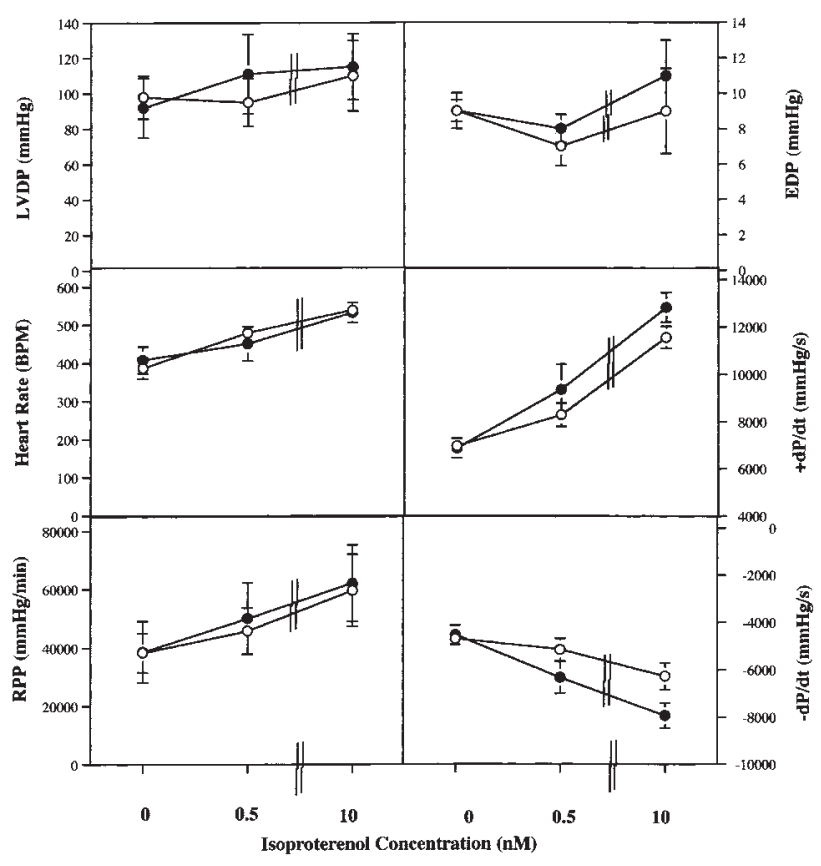

\section{Figure 7}

Isovolumic contractile performance in wild-type mice (open circles) and $\mathrm{G}_{4} \mathrm{H}^{-/-}$mice (closed circles) in response to 2 doses of isoproterenol as described in Methods. There are 5 animals ( 3 males and 2 females) in each group (32-40 weeks of age). Each $\mathrm{G} 4 \mathrm{H}^{-1-}$ mouse was paired with an age-matched wild-type control. LVDP, left ventricular developed pressure; EDP, end diastolic pressure; RPP, rate pressure product; $+\mathrm{dP} / \mathrm{dt}$, rate of contraction; $-\mathrm{dP} / \mathrm{dt}$, rate of relaxation. 
Table 3

Contractile performance of isolated perfused hearts

\begin{tabular}{lcccccc}
\hline & $n$ & LVSP $(\mathrm{mmHg})$ & EDP $(\mathrm{mmHg})$ & Heart rate (beats $/ \mathrm{min})$ & $\mathrm{RPP}\left(\times 10^{3} \mathrm{mmHg} / \mathrm{min}\right)$ & $\mathrm{CF} / \mathrm{g}(\mathrm{mL} / \mathrm{g}$ per minute $)$ \\
$\mathrm{G} 4 \mathrm{H}^{-1-}$ male & 6 & $104 \pm 7$ & $5.3 \pm 0.9$ & $291 \pm 14$ & $28.8 \pm 2.5$ & $16.1 \pm 3.7$ \\
WT male & 6 & $105 \pm 11$ & $6.5 \pm 0.6$ & $327 \pm 17$ & $31.4 \pm 3.1$ & $14.9 \pm 2.8$ \\
G4H $4 H^{-1}$ female & 8 & $119 \pm 9$ & $5.5 \pm 0.4$ & $289 \pm 19$ & $32.7 \pm 3.6$ & $13.5 \pm 0.7$ \\
WT female & 8 & $99 \pm 7$ & $5.4 \pm 0.3$ & $307 \pm 16$ & $28.2 \pm 1.5$ & $14.8 \pm 0.9$
\end{tabular}

LVSP, left ventricular systolic pressure; EDP, end-diastolic pressure; RPP, rate pressure product; CF/g, coronary flow per gram heart weight. Mice were agematched. Mean age of males: $40 \pm 2$ weeks; mean age of females: $38 \pm 2$ weeks. Heart weights are similar to those shown in Table $2 \mathrm{~b}$. There were no significant differences in any parameter between wild-type and $\mathrm{G}_{4 \mathrm{H}^{-1-}}$ mice of either sex by ANOVA.

circulating concentrations of insulin and cardiac metabolic substrates. The observed hypertrophy is intermediate in degree between the physiological hypertrophy observed after exercise training in rodents $(40,41)$ and the more severe changes observed in pathological conditions such as hypertension or pressure overload (26, 42). In $\mathrm{G}_{4} \mathrm{H}^{-/-}$mice, there was no histological evidence of myocyte disarray and no increase in myocardial fibrosis - both common features of pathological hypertrophy $(30,43)$. Furthermore, the mild induction of ANP gene expression is similar to that reported with chronic exercise in the rat, but less than that observed in hypertensive rats (42). The induction of natriuretic peptide gene expression is one of the most conserved features of ventricular hypertrophy (irrespective of the etiology of the hypertrophy; 44) and is observed in multiple species (38). BNP is expressed predominantly in ventricular myocytes, and its expression and secretion are more closely correlated with changes in ventricular mass than are the expression and secretion of ANP (44). Hence the significant increase in BNP expression provides strong evidence for the presence of myocyte hypertrophy in $\mathrm{G}_{4} \mathrm{H}^{-/-}$mice. The molecular mechanisms inducing hypertrophy in this model are not currently understood. Our study raises the possibility that the inability to increase cardiac glucose uptake by GLUT4 results in the activation of signaling pathways that ultimately lead to the development of cardiac hypertrophy.

Isovolumic contractile performance is preserved in $\mathrm{G}_{4} \mathrm{H}^{-/}$hearts under the experimental conditions described here. In response to the inotropic stimulant isoproterenol, wild-type and $\mathrm{G} \mathrm{H}^{-/-}$hearts achieved heart rates similar to those observed in vivo, and experienced increased contractile performance to a similar extent. However, in preliminary experiments, we observed that isolated perfused $\mathrm{G}_{4} \mathrm{H}^{-/-}$hearts have increased susceptibility to ischemic injury, and develop irreversible diastolic dysfunction after low-flow ischemia $(45,46)$. In preliminary in vivo experiments performed under ketamine/xylazine anesthesia, blood pressures and basal in vivo contractility were similar in $\mathrm{G} 4 \mathrm{H}^{-/-}$mice and control mice (47). However, diastolic dysfunction developed in $\mathrm{G}_{4} \mathrm{H}^{-/-}$mice after isoproterenol administration. In these experiments, the anesthesia resulted in reduced baseline heart rate and diminished cardiac contractility in both groups. Therefore the basis of the diastolic dysfunction in response to isoproterenol under these in vivo conditions requires further investigation. Taken together, these observations suggest that under basal conditions, the GLUT4deficient heart is capable of maintaining normal function, and that dysfunction occurs only in the context of significant stress, such as ischemia.

Another major finding is that deletion of GLUT4 expression in the heart is associated with induction of GLUT1 expression. The degree of GLUT1 upregulation in $\mathrm{G}_{4} \mathrm{H}^{-/-}$mice is similar to that reported in GLUT4null mice (29). Cardiac GLUT1 expression has been reported to increase during euglycemic hyperinsulinemic clamps in rats (21). The upregulation was blunted by increasing glucose or FFA concentration, suggesting that both insulin exposure and the energy status of cardiac muscle could be important determinants of cardiac GLUT1 expression. GLUT4-null mice develop substantial hyperinsulinemia and reduced concentrations of FFAs, which could account in part for the upregulation of GLUT1. However, our mice with cardiac-selective loss of GLUT4 are not hyperinsulinemic and have normal serum concentrations of FFAs and glucose. Therefore it is more likely that GLUT1 induction results directly from the effects of GLUT4 deficiency in cardiomyocytes, and from altered signal transduction pathways that ultimately lead to hypertrophy.

The degree of upregulation of basal transport and GLUT1 expression observed in $\mathrm{G}_{4} \mathrm{H}^{-/-}$hearts is similar to that reported in aortically banded rats with compensated hypertrophy (7), and in the hearts of spontaneously hypertensive rats (26). Recent evidence suggests that activation of the Ras, Raf, MEK, and ERK pathways, which may play a role in the induction of cardiac hypertrophy $(48,49)$, is associated with induction of GLUT1 expression (27). These pathways also activate the expression of ANP (50). Furthermore, additional pathways involving members of the stress-activated protein kinase family such as JNK have also been shown to be important mediators of the hypertrophic response in vivo (51). Our model of cardiac GLUT4 deficiency will therefore be a useful model system with which to dissect the interactions between changes in cardiac glucose utilization and activation of signal transduction pathways that lead to hypertrophy.

Our studies support the hypothesis that GLUT1 is an important mediator of basal glucose uptake in the 
heart. The absence of GLUT4 was not associated with a reduction in basal glucose uptake. On the contrary, basal glucose uptake was increased in the hearts of $\mathrm{G}_{4} \mathrm{H}^{-/-}$mice; this correlated with the increase in GLUT1 expression. This contrasts with adipose tissue and skeletal muscle, in which GLUT4 is the major mediator of basal glucose uptake (17-19). Insulin induces translocation of the GLUT1 transporter in the heart in vivo $(13,52)$, in primary rat adipocytes $(17)$, and in 3T3L1 adipocytes (53). GLUT1 also translocates to the plasma membrane in the heart in response to ischemia (14). The lack of augmentation of glucose uptake in GLUT4-deficient hearts in response to a maximally stimulating dose of insulin confirms that GLUT4 is the major mediator of insulin-mediated glucose uptake in the heart.

Our findings support those of Katz et al., who initially reported the development of cardiac hypertrophy in mice that lacked GLUT4 in all tissues (GLUT4-null) (29). There are, however, important differences between GLUT4-null mice and our mice, which lack the transporter selectively in the heart. Of note, $\mathrm{G}_{4} \mathrm{H}^{-/-}$mice have normal longevity in contrast to GLUT4-null mice, the majority of which died between 5 and 7 months of age (29). $\mathrm{G} 4 \mathrm{H}^{-/-}$mice have a normal metabolic profile (29), the degree of cardiac hypertrophy is modest, there is no myocardial fibrosis (54), and ventricular function is preserved (55). The milder cardiac phenotype in our mice is consistent with the hypothesis that reduced substrate supply and hyperinsulinemia impaired cardiac function and induced further cardiac hypertrophy in GLUT4-null mice. Diminished oxidation of longchain fatty acids is associated with the development of cardiac hypertrophy in rodents (56). Chronic hyperinsulinemia is associated with ventricular hypertrophy in rats (57), and reversal of hyperinsulinemia in GLUT4 heterozygous-null mice with transgenic complementation of GLUT4 in skeletal muscle leads to regression of cardiac hypertrophy (31). The absence of multiple metabolic derangements in our animals provides a plausible explanation for the difference in the cardiac phenotypes of $\mathrm{G}_{4} \mathrm{H}^{-/-}$mice vs. GLUT4-null mice. It is also possible that differences in the genetic background of these 2 models could account for some of the differences in the magnitude of cardiac hypertrophy and in contractile function. Importantly, both models define a critical role for GLUT4 in cardiac physiology. The absence of GLUT4 results in compensated hypertrophy in $\mathrm{G}_{4} \mathrm{H}^{-/-}$mice, and in overt cardiac dysfunction when the heart is subjected to additional metabolic stresses as occurs in GLUT4-null animals.

In conclusion, we have shown that cardiac-selective GLUT4 deficiency leads to compensated ventricular hypertrophy with preserved cardiac contractile function. These changes do not impair longevity. The upregulation of GLUT1 and the increase in basal cardiac glucose uptake is similar to that observed in other models of cardiac hypertrophy. Our observations raise the important possibility that primary alterations in cardiac glucose transporter expression may play a direct role in the pathogenesis of cardiac hypertrophy.

\section{Acknowledgments}

This work was supported by National Institutes of Health (NIH) grants HL-62886 and DK-02495 (to E.D. Abel), HL-59246 and AG-00837 (to R. Tian), HL-52320 (to J. Ingwall), and DK-43051 (to B.B. Kahn) and the transgenic core of the Boston Obesity Nutrition Research Center (P30DK 46200). E.D. Abel was the recipient of a Faculty Development Award from the Robert Wood Johnson Foundation, recipient of the Eleanor and Miles Shore 50th Anniversary Scholars in Medicine Fellowship from Harvard Medical School, and recipient of a pilot and feasibility grant from the Boston Obesity and Nutrition Research Center (P30 DK46200). H. Kaulbach was supported by NIH training grant T32-DK07561. J. Duffy and T. Doetschmann wished to express their thanks to Mark Lewandowski and Gail Martin for the gift of the cre recombinase plasmid. We also thank Odile Peroni, Mark Pham, Dionne Rudder, Sandrine Betuing, and Mikhail Yeframashvili for technical assistance. One of the authors, John Duffy, passed away during the preparation of this manuscript. We therefore dedicate this work to his memory.

1. Taegtmeyer, H. 1994. Energy metabolism of the heart: from basic concepts to clinical applications. Curr. Probl. Cardiol. 19:57-116.

2. Gertz, E.W., Wisneski, J.A., Stanley, W.C., and Neese, R.A. 1988. Myocardial substrate utilization during exercise in humans. Dual carbonlabeled carbohydrate isotope experiments. J. Clin. Invest. 82:2017-2025.

3. Seymour, A.M., Eldar, H., and Radda, G.K. 1990. Hyperthyroidism results in increased glycolytic capacity in the rat heart. A 31P-NMR study. Biochim. Biophys. Acta. 1055:107-116.

4. Opie, L.H. 1990. Myocardial ischemia-metabolic pathways and implications of increased glycolysis. Cardiovasc. Drugs Ther. 4:777-790.

5. Owen, P., Dennis, S., and Opie, L.H. 1990. Glucose flux rate regulates onset of ischemic contracture in globally underperfused rat hearts. Circ. Res. 66:344-354.

6. Nascimben, L., et al. 1995. Rates of insulin-independent glucose entry and glycolysis are increased in hypertrophied hearts. Circulation. 92(Suppl. I):I-770. (Abstr.)

7. Weinberg, E.O., Thienelt, C.D., and Lorell, B.H. 1995. Pretranslational regulation of glucose transporter isoform expression in hearts with pressure-overload left ventricular hypertrophy. Circulation. 92(Suppl. I):I-385. (Abstr.)

8. Manchester, J., Kong, X., Nerbonne, J., Lowry, O.H., and Lawrence, J.C., Jr. 1994. Glucose transport and phosphorylation in single cardiac myocytes: rate-limiting steps in glucose metabolism. Am. J. Physiol. 266:E326-E333.

9. Mueckler, M. 1990. Family of glucose transporter genes. Implications for glucose homeostasis and diabetes. Diabetes. 39:6-11.

10. Bell, G.I., et al. 1990. Molecular biology of mammalian glucose transporters. Diabetes Care. 13:198-208.

11. Slot, J.W., Geuze, H.J., Gigengack, S., James, D.E., and Lienhard, G.E. 1991. Translocation of the glucose transporter GLUT4 in cardiac myocytes of the rat. Proc. Natl. Acad. Sci. USA. 88:7815-7819.

12. Egert, S., Nguyen, N., Brosius, F.C., III, and Schwaiger, M. 1997. Effects of wortmannin on insulin- and ischemia-induced stimulation of GLUT4 translocation and FDG uptake in perfused rat hearts. Cardiovasc. Res. 35:283-293.

13. Russell, R.R., III, et al. 1998. Additive effects of hyperinsulinemia and ischemia on myocardial GLUT1 and GLUT4 translocation in vivo. Circulation. 98:2180-2186.

14. Young, L.H., et al. 1997. Low-flow ischemia leads to translocation of canine heart GLUT-4 and GLUT-1 glucose transporters to the sarcolemma in vivo. Circulation. 95:415-422.

15. Sun, D., Nguyen, N., Degrado, T.R., Schwaiger, M., and Brosius, F.C. 1994. Ischemia induces translocation of the insulin-responsive glucose transporter GLUT4 to the plasma membrane of cardiac myocytes. Cir- 
culation. 89:793-798.

16. Till, M., Kolter, T., and Eckel, J. 1997. Molecular mechanisms of contraction-induced translocation of GLUT4 in isolated cardiomyocytes. Am. J. Cardiol. 80:85A-89A.

17. Holman, G.D., et al. 1990. Cell surface labeling of glucose transporter isoform GLUT4 by bis-mannose photolabel. Correlation with stimulation of glucose transport in rat adipose cells by insulin and phorbol ester. J. Biol. Chem. 265:18172-18179.

18. Dudek, R.W., Dohm, G.L., Holman, G.D., Cushman, S.W., and Wilson, C.M. 1994. Glucose transporter localization in rat skeletal muscle. Autoradiographic study using ATB-[2-3H]BMPA photolabel. FEBS Lett. 339:205-208.

19. Kahn, B.B., Rossetti, L., Lodish, H.F., and Charron, M.J. 1991. Decreased in vivo glucose uptake but normal expression of GLUT1 and GLUT4 in skeletal muscle of diabetic rats. J. Clin. Invest. 87:2197-2206.

20. Kraegen, E.W., et al. 1993. Glucose transporters and in vivo glucose uptake in skeletal and cardiac muscle: fasting, insulin stimulation and immunoisolation studies of GLUT1 and GLUT4. Biochem. J. 295:287-293.

21. Laybutt, D.R., Thompson, A.L., Cooney, G.J., and Kraegen, E.W. 1997. Selective chronic regulation of GLUT1 and GLUT4 content by insulin, glucose, and lipid in rat cardiac muscle in vivo. Am. J. Physiol. 273:H1309-H1316.

22. Burcelin, R., et al. 1993. Regulation of glucose transporter and hexokinase II expression in tissues of diabetic rats. Am. J. Physiol. 265:E392-E401.

23. Slieker, L.J., et al. 1992. Glucose transporter levels in tissues of spontaneously diabetic Zucker fa/fa rat (ZDF/drt) and viable yellow mouse (Avy/a). Diabetes. 41:187-193.

24. Kainulainen, H., et al. 1994. In vivo glucose uptake and glucose transporter proteins GLUT1 and GLUT4 in heart and various types of skeletal muscle from streptozotocin-diabetic rats. Biochim. Biophys. Acta. 1225:275-282

25. Garvey, W.T., Hardin, D., Juhaszova, M., and Dominguez, J.H. 1993. Effects of diabetes on myocardial glucose transport system in rats: implications for diabetic cardiomyopathy. Am. J. Physiol. 264:H837-H844.

26. Paternostro, G., Clarke, K., Heath, J., Seymour, A.M., and Radda, G.K. 1995. Decreased GLUT-4 mRNA content and insulin-sensitive deoxyglucose uptake show insulin resistance in the hypertensive rat heart. Cardiovasc. Res. 30:205-211.

27. Montessuit, C., and Thorburn, A. 1999. Transcriptional activation of the glucose transporter GLUT1 in ventricular cardiac myocytes by hypertrophic agonists. J. Biol. Chem. 274:9006-9012.

28. Brosius, F.C., III, et al. 1997. Persistent myocardial ischemia increases GLUT1 glucose transporter expression in both ischemic and nonischemic heart regions. J. Mol. Cell. Cardiol. 29:1675-1685.

29. Katz, E.B., Stenbit, A.E., Hatton, K., Depinho, R., and Charron, M.J. 1995. Cardiac and adipose tissue abnormalities but not diabetes in mice deficient in GLUT4. Nature. 377:151-155.

30. Stenbit, A.E., et al. 1997. GLUT4 heterozygous knockout mice develop muscle insulin resistance and diabetes. Nat.Med. 3:1096-1101.

31. Tsao, T.S., et al. 1999. Prevention of insulin resistance and diabetes in mice heterozygous for GLUT4 ablation by transgenic complementation of GLUT4 in skeletal muscle. Diabetes. 48:775-782.

32. Rajewsky, K., et al. 1996. Conditional gene targeting. J. Clin. Invest. 98:600-603.

33. Li, E., Bestor, T.H., and Jaenisch, R. 1992. Targeted mutation of the DNA methyltransferase gene results in embryonic lethality. Cell. 69:915-926.

34. Papaioannou, V., and Johnson, R. 1993. Production of chimeras and genetically defined offspring from targeted ES cells. In Gene targeting: a practical approach. A.L. Joyner, editor. Oxford University Press. Oxford, United Kingdom. 107-146.

35. Subramaniam, A., et al. 1991. Tissue-specific regulation of the alphamyosin heavy chain gene promoter in transgenic mice. J. Biol. Chem. 266:24613-24620.

36. Frevert, E.U., and Kahn, B.B. 1996. Protein kinase C isoforms $\varepsilon, \eta, \delta$, and $\zeta$, in murine adipocytes: expression, subcellular localization and tissue- specific regulation in insulin-resistant states. Biochem. J. 316:865-871.

37. Armstrong, A.T., Binkley, P.F., Baker, P.B., Myerowitz, P.D., and Leier, C.V. 1998. Quantitative investigation of cardiomyocyte hypertrophy and myocardial fibrosis over 6 years after cardiac transplantation. J. Am. Coll. Cardiol. 32:704-710.

38. Chien, K.R., Knowlton, K.U., Zhu, H., and Chien, S. 1991. Regulation of cardiac gene expression during myocardial growth and hypertrophy: molecular studies of an adaptive physiologic response. FASEB J. 5:3037-3046.

39. Fujiwara, H., and Nishigaki, K. 1998. Brain natriuretic peptide in hypertrophic obstructive cardiomyopathy. Cardiologia. 43:901-908.

40. Kaplan, M.L., et al. 1994. Cardiac adaptations to chronic exercise in mice. Am. J. Physiol. 267:H1167-H1173.

41. Hickson, R.C., Hammons, G.T., and Holoszy, J.O. 1979. Development and regression of exercise-induced cardiac hypertrophy in rats. Am. J. Physiol. 236:H268-H272.

42. Buttrick, P.M., Kaplan, M., Leinwand, L.A., and Scheuer, J. 1994. Alterations in gene expression in the rat heart after chronic pathological and physiological loads. J. Mol. Cell. Cardiol. 26:61-67.

43. Factor, S.M., Minase, T., and Sonnenblick, E.H. 1980. Clinical and morphological features of human hypertensive-diabetic cardiomyopathy. Am. Heart J. 99:446-458.

44. Sagnella, G.A. 1998. Measurement and significance of circulating natriuretic peptides in cardiovascular disease. Clin. Sci. (Colch.) 95:519-529.

45. Tian, R., Pham, M., and Abel, E.D. 1999. Cardiac glucose transporter deficiency increases the susceptibility of the heart to ischemic injury. Diabetes. 48 (Suppl. 1):A127. (Abstr.)

46. Tian, R., Pham, M., and Abel, E.D. 1999. Cardiac selective GLUT4 ablation exacerbates ATP depletion and contractile dysfunction during low flow ischemia. Circulation. 100 (Suppl. I):I-344. (Abstr.)

47. Hampton, T., Wang, J.-F., Deangelis, J., and Abel, E.D. 1999. Preserved basal contractility but impaired responses to isoproterenol in vivo in mice with cardiac selective GLUT4 ablation. Circulation. 100(Suppl. I):I118. (Abstr.)

48. Bogoyevitch, M.A., et al. 1994. Endothelin-1 and fibroblast growth factors stimulate the mitogen-activated protein kinase signaling cascade in cardiac myocytes. The potential role of the cascade in the integration of two signaling pathways leading to myocyte hypertrophy. J. Biol. Chem. 269:1110-1119.

49. Sadoshima, J., and Izumo, S. 1993. Mechanical stretch rapidly activates multiple signal transduction pathways in cardiac myocytes: potential involvement of an autocrine/paracrine mechanism. EMBO J. 12:1681-1692.

50. Bogoyevitch, M.A., et al. 1996. Adrenergic receptor stimulation of the mitogen-activated protein kinase cascade and cardiac hypertrophy. Biochem. J. 314:115-121.

51. Sugden, P.H., and Clerk, A. 1998. "Stress-responsive" mitogen-activated protein kinases (c-Jun N-terminal kinases and p38 mitogen-activated protein kinases) in the myocardium. Circ. Res. 83:345-352.

52. Fischer, Y., et al. 1997. Insulin-induced recruitment of glucose transporter 4 (GLUT4) and GLUT1 in isolated rat cardiac myocytes. Evidence of the existence of different intracellular GLUT4 vesicle populations. J. Biol. Chem. 272:7085-7092.

53. Clarke, J.F., Young, P.W., Yonezawa, K., Kasuga, M., and Holman, G.D 1994. Inhibition of the translocation of GLUT1 and GLUT4 in 3T3-L1 cells by the phosphatidylinositol 3-kinase inhibitor, wortmannin. Biochem. J. 300:631-635.

54. Laidlaw, J.S., Jelicks, L.A., and Charron, M.J. 1999. Metabolically altered and hypertrophied GLUT4-null hearts resist loss of function following ischemia/reperfusion. Diabetes. 48 (Suppl. 1):A75. (Abstr.)

55. Weiss, R.G., et al. 1998. In vivo cardiac energetics in GLUT4-null mice. Circulation. 98(Suppl. I):I-627. (Abstr.)

56. Bressler, R., and Goldman, S. 1993. A role of fatty acid oxidation in cardiac hypertrophy. Cardioscience. 4:133-142.

57. Holmang, A., Yoshida, N., Jennische, E., Waldenstrom, A., and Bjorntorp, P. 1996. The effects of hyperinsulinaemia on myocardial mass, blood pressure regulation and central haemodynamics in rats. Eur. J. Clin. Invest. 26:973-978. 